\title{
Whose Children? Protecting Unaccompanied Migrant Children in Europe: A Case of Diffused Responsibility?
}

\author{
Ingi Iusmen \\ Department of Politics and International Relations, University of \\ Southampton, Southampton, UK \\ i.iusmen@soton.ac.uk
}

\begin{abstract}
This paper examines the reasons behind the failure of EU and national policy interventions to protect unaccompanied migrant children's (unaccompanied minors - UAMs) rights during the refugee crisis in Europe. By drawing on policy documents and empirical data, it is argued that the deficient protection of UAM s' child rights was essentially a failure of responsibility allocation in line with the "bystander effect" analytical explanation. While this argument does not disregard the role of other explanatory factors, such as the lack of European solidarity, poor legal enforcement and financial reasons, among others, it is claimed that the diffusion of responsibility (in theory and practice) between various policy systems at the national level, as well as between the EU and domestic levels, contributed to the failure to protect UAM s' child rights across Europe.
\end{abstract}

\section{Keywords}

bystander effect - children's rights - diffused responsibility - unaccompanied migrant children

The years $2015^{-16}$ saw an unprecedented number of refugees arriving in the European Union (EU). The media coverage of the suffering faced by migrant children arriving in Europe augmented the feeling of crisis (Niemann and 
Zaun, 2018) of human rights provision and unearthed the legal, policy and institutional shortcomings in their protection. In 2016 nearly every one in four asylum applicants in the EU was a child (European Commission, 2017). Despite this influx of child refugees, the efficiency and adequacy of European and national responses to address their plight has been limited and questionable. Not only did the refugee ${ }^{1}$ crisis test the effectiveness of the Common European Asylum System (CEAS) in coping with an unprecedented influx of migrants, but it also revealed the existing legal and policy loopholes in human rights protection, more generally, and in children's rights protection, more particularly. Indeed, the refugee crisis has exposed the enduring 'child protection deficits' (Bhabha, 2019) faced by child refugees at the national level across Europe (Save the Children, 2017). The legal provisions in the CEAS afforded limited opportunities for the protection of children's rights in line with the UN Convention on the Rights of the Child (CRC) principles (Smyth, 2014), while child protection and social services in the European countries proved ineffective and unable to address the violation of child refugees' rights.

Within the migrant children's group, the category of unaccompanied migrant children (unaccompanied minors - UAM s) ${ }^{2}$ has a particularly vulnerable situation, given that the protection of their rights falls through the cracks of various policy systems, such as the asylum, immigration or child protection systems. Indeed, UAM s face an exceptionally grim situation due to ineffective protection policies as well as being exposed to a broader attitude of 'victimisation and criminalisation' (Ayotte, 2000) towards them across Europe. The 'culture of disbelief and suspicion' (House of Lords, 2016:3) vis-a-vis the UAM s at the national level as well as the poor implementation of the existing EU and national measures relevant to this category of child refugees, further increased the vulnerability and victimisation suffered by UAM s during the migrant crisis. The protection of UAM s' rights seemed to fall through the cracks of European and national legal and policy systems during the crisis. How can the failure to protect UAM s' child rights in Europe - during the 2015-16 refugee crisis - be explained? Why did the protection of UAM s' rights fail across the EU Member States?

1 I use "refugee crisis" interchangeably with the "migrant crisis" to refer to the influx of migrants and refugees that affected Europe from 2015 onwards.

2 'Unaccompanied children' refers to the category of children - as defined by the UN Convention on the Rights of the Child - who are outside their country of origin and who have been separated from both parents and other relatives and are not being cared for by an adult who, by law, is responsible for doing so. It includes a child who is left unaccompanied after they have entered the territory of an EU Member State (Art. 2(1) of the Directive 2011/95/EU Recast Qualification Directive). 
By drawing on a wide range of primary and secondary documentary analysis, as well as informal discussions with UK and EU stakeholders (NGO s, children's organisations and networks, legal experts and practitioners) and analysis of available empirical data, this paper sets out to investigate the factors explaining the failure of EU and national policy interventions to uphold UAM s' rights during the recent refugee crisis. While not focusing on specific EU Member States, this paper examines the similar policy failures and shortcomings across Europe that led to the poor enforcement of UAM s' rights. The central argument is that the deficient protection of UAM s' children's rights was facilitated, among others, by a failure of responsibility allocation in line with the "bystander effect" analytical explanation. While this argument does not overlook the importance of other factors, such as the lack of European solidarity to protect refugees, ${ }^{3}$ poor legal enforcement and financial reasons - it is argued that the diffusion of responsibility among various policy systems contributed to the protection failures experienced by UAM $\mathrm{s}$. The fragmented policy responsibilities regarding UAM s' rights - both vertically, i.e. between the EU, national and local levels, as well as horizontally - across national policy sectors - led to a vacuum of mandate or ownership concerning the protection of UAM s. The responsibility diffusion is interpreted both as a policy design issue, as well as a matter of deficient policy implementation that became evident due to the influx of child refugees. In essence, the paper unveils the legislative and policy gaps - at national and supranational levels - that acted as a transmission belt to diffuse the responsibility for UAM s' protection. Empirically, the findings of this paper provide evidence shedding light on some of the key factors conducive to the marginalisation and victimisation of UAM s during the refugee crisis. Analytically, the fragmented and diffused responsibility is explained via the "bystander effect" conceptual framework by highlighting that multi-layered policy systems - such as asylum, immigration, child protection, family reunification etc. - within a multi-tiered system of governance, often fail to work in a coordinated, multi-disciplinary and integrated manner due to structural design and implementation deficiencies. In essence, the diffused responsibility acted as a catalyst compounding the impact of other factors on the UAM s' protection failures. The key academic advancements consist of deploying the 'bystander effect' concept from social psychology, generally used to explain individual behaviour in relation to group behaviour, to illustrate how institutional, legal and policy gaps acted as mechanisms - at national and European

3 See special issue in JCMS (2018), 'EU Refugee Policies and Politics in Times of Crisis', (2018) 56(1) and Agustín, Ó. G. and Jørgensen, M. B., Solidarity and the 'refugee Crisis' in Europe (Springer, 2018). 
levels - facilitating the diffusion of responsibility for the protection of UAM $\mathrm{s}$ during the refugee crisis.

The first section sets out the legal and policy approaches regarding child refugees, section two discusses the refugee crisis and its impact on UAM s, while section three introduces the analytical framework, which is then employed to explain the empirical data.

This section shows how and why the legal and policy protection of child refugees, particularly UAM s, has been challenging both at international and European levels.

\subsection{Child Refugees and the CRC}

The protection of refugee children is not well defined and addressed by the international instruments relevant to this category of children. The status of asylum-seeking children is to a certain extent vague and uncertain, as non-citizens or aliens (Benhabib, 2004) and as children, generally regarded as 'apolitical' (Nakata, 2015) with rights not fully enforced at the domestic level. The primary international instrument governing the rights and status of refugees under international law, namely the 1951 Convention Relating to the Status of Refugees - the Geneva Refugee Convention - adopted by the United Nations High Commissioner for Refugees (UNHCR), makes no reference to refugee children. Article $1 \mathrm{~A}(2)$ on refugee status makes no specific reference to children and therefore, it has been claimed that due to this significant absence, the Refugee Convention has been interpreted and applied via an 'adult-focused lens' (Crock, 2006: 244). As Bhabha (2003: 266) rightly put it, children seeking asylum or refugee protection rarely benefit from either, primarily due to the fact that children have simply not been thought of as appropriate subjects of asylum applications or refugee status grants'. According to the UNHCR, refugee children predominantly face two types of challenges when attempting to access international refugee protection (Pobjoy, 2017: 3). First, it is the challenge of invisibility: namely the failure to recognise the child's status as a refugee. Second, there is the challenge of incorrect assessment, namely 'in cases where a child's claim is assessed independently, a failure to interpret the Convention [Refugee Convention] in a manner that takes into account the fact that the applicant is in fact a child' (Pobjoy, 2017:3).

The key tensions between the international protection of children's rights in line with the standards and principles enshrined in the CRC and enforced 
immigration control have been widely debated by scholars (Watters 2007; Vitus and Liden 2010; Bhabha 2009, 2014, Allsopp and Chase 2019). The CRC has globally and nationally been accepted as the main children's rights instrument contributing to 'standard setting, implementation and monitoring' (Hanson, 2014) in relation to children's policies. Therefore, in an asylum and refugee context, the CRC should provide the most substantive framework of minimum standards and obligations that national authorities owe to a refugee child. Arguably, the CRC could inform the Refugee Convention in two significant ways (Pobjoy, 2017: 6-7). First, the CRC could be used as a procedural guarantee informing the refugee determination process, while second, the CRC could provide an interpretative aid informing the application of the Refugee Convention definition of "refugees" by taking into account the broader international human rights instruments. However, in practice UAM s are often faced with an 'ambivalent' approach (Bhabha, 2014) by state authorities when it comes to their protection. UAM s have to deal with contradictory messages as at times, some legal and administrative procedures are strongly protective (e.g. children placed in facilities with unrelated adults), while at other times they are resolutely punitive (e.g. children being returned to dangerous places) (see Bhabha, 2014: 207). In essence, child migrants are caught between protectionist and delinquency approaches (Crawley, 2010) or are part of an 'uneasy marriage of a system merging two bodies of law without coherency' (Farmer, 2018: 178).

The protection of UAM $\mathrm{s}$ has further challenged the legal and policy approaches to child refugees. In the absence of parents, the focus shifted to the status of UAM s as "children" which, consequently, triggered the need to address the legal status and rights of children in international refugee and asylum law. This meant that, in practical terms, it did become necessary for states to address a child's claim for international protection when the child arrived unaccompanied in that respective country (Bhabha, 2014). Notably, the arrival of UAM s has led to a legal paradigm-shift in terms of how refugee children are treated by national and supranational legislation and policy: in practice this meant that UAM s acquired the right to apply for refugee status and, therefore, their rights as children could be protected as part of this process. Nevertheless, there have been limited and fragmented provisions in EU asylum law that have focused on the rights and entitlements of UAM s in the Union. Moreover, while UAM s have recently acquired some policy advancements, such as guardianship or limits on detention etc., the incoherency of the global migration system renders that protection incomplete (Bhabha, 2014: 241). As shown below, the CEAS includes important provisions that address the situation of refugee and asylum-seeking children; however, it fails to target the specificities and complexity of UAM s' situation. 


\subsection{Common European Asylum System (CEAS), Children's Rights and UAMS}

The emergence of a CEAS since the late 1990s has been hailed as a concerted European effort whereby the EU Member States would gradually harmonise their asylum procedures and policies. The promotion of "securitisation" as "fortress Europe" was the underlying objective of the EU migration and asylum policies (Guild, 2006), which led to the subsequent focus on migration control and security at the expense of the human rights protection of refugees and asylum-seekers. The prioritisation of security objectives at the expense of the asylum-seekers' human rights protection was also evidenced by the limited provisions aimed at protecting the rights of the child in the CEAs. To address this, since 2009 the EU has adopted a set of revised or recast laws that make up the core of the CEAs. These included the recast versions of the Asylum Procedures, Reception Conditions and Qualification Directives, as well as the Dublin III Regulation, which were aimed at strengthening the legal protection of child refugees. These recast laws include some child-specific provisions, such as child participation, right to the support of a guardian or legal representative, right to family reunification, "child friendly" adaptations to the physical environment and references to the "best interest of the child" principle. Despite these, the child specific provisions in the CEAs rules fall short of advancing a rights-based approach in relation to refugee children. On the contrary, it has been shown that the child rights agenda is undermined by the larger migration control agenda that underpins the CEAS, and as an upshot of this, a contradictory image of the child (Smyth, 2014: 236) - needy and vulnerable versus able and with agency - emerges from the CEAS provisions.

Despite the EU's recast CEAS laws, there are still significant gaps in the EU asylum acquis with respect to UAM s. For instance, there are limited child-specific provisions with respect to the conditions of entry of UAM s (European Migration Network 2015) and the "best interests of the child" principle is not applied in a comprehensive manner or even at all. Furthermore, while there is EU asylum law applicable to those UAM s seeking asylum, there are only few specific provisions in the EU legislation - relevant to UAM s - who arrive in the EU, yet do not apply for international protection. It should be noted that, in compliance with $\mathrm{EU}$ acquis, national governments have to meet the specific minimum safeguards for those UAM s applying for asylum in the EU. Generally, these safeguard measures vary significantly across the Member States. At the same time, the non-asylum seeking UAM s face more challenges, given that some of the Member States do not have legislation that distinguishes between this category of UAM s and those who seek asylum, and therefore treat the former as third country nationals. Above all, reconciling 
child protection and migration goals is even more difficult across borders, within the EU (O'Donnell, 2018).

Furthermore, UAM s face a particularly vulnerable situation as their rights and protection can easily fall through the cracks of various policy systems, such as the asylum/immigration and child protection ones. The UAM s in Europe struggle with an extremely precarious situation due to the lack of clarity regarding the responsibility for migrant children at the national level in general, and UAM s in particular (AIDA, 2017). Additionally, UAM s are often confronted with limited protection and insufficient access to services, as well as slow family reunification, relocation and asylum procedures: all these challenges render them vulnerable and at high risk of abuse and trafficking. It is unclear which policy area or system should take responsibility for UAM s' welfare, for the policy systems' coordination, steering and for the enforcement of minimum standards of protection and provision of rights. While these shortcomings vary across the Member States, as it will be shown below, the diffusion of responsibility for UAM s' rights protection between various policy systems was a predominant problem during the refugee crisis.

\section{$3 \quad$ Refugee Crisis and Unaccompanied Migrant Children}

The refugee crisis that hit Europe starting with 2015 further disclosed the deficiencies and failures of the CEAS and national policies to assist and protect UAM s. Despite having a policy approach - Commission's Action Plan on Unaccompanied Minors (2010-2014) - aimed at UAM s in the EU, the European institutions failed to provide a concerted and coherent response to the plight of UAM s during the refugee crisis. The Action Plan focused on three main strands for action: prevention, regional protection programmes, reception and identification of durable solutions, and was intended to be implemented alongside the CEAS provisions relevant to UAM s. The Plan highlights the importance of placing the CRC standards, 'at the heart of any action concerning unaccompanied minors' (European Commission, 2010: 2). However, in practice the EU's Action Plan was poorly implemented (House of Lords, 2016) and subsequently, the Commission decided not to renew it. Furthermore, this action plan was not designed to address a migrant crisis, like the one that occurred in $2015^{-16}$.

In 2018, the vast majority of child refugees arriving in Europe were UAM s. According to official figures (UNICEF, 2018) 200,973 children arrived in Italy, Spain and Bulgaria, of whom 20,325 (10 per cent) were UAM s. In 2018, the countries that received high numbers of children seeking asylum, including UAM s, are Germany $(78,270)$, Greece $(21,770)$, France $(24,145)$, Italy $(8,535)$ the 
UK $(8,975)$, and Spain $(11,035)$. Some countries, such as Poland or Hungary, chose to restrict the numbers of migrants that could enter their territory and claim asylum. Countries such as the UK, given their selective implementation of the CEAS measures, ${ }^{4}$ accepted UAM s, via their own national schemes, such as the Dubs scheme ${ }^{5}$ or via the Dublin III Regulation. Nevertheless, despite these differences - for instance it has been shown that the Nordic states have fared better regarding the provision of UAM s' children's rights ${ }^{6}$ - unaccompanied migrant children faced similar violations of rights across Europe: these are discussed in the sections below along with some of the explanatory factors.

\subsection{Child Rights Violations}

Evidence shows that one of the key failures vis-à-vis the UAM s recently arriving in Europe was linked to enforcement of their children's rights, particularly the CRC principles such as child participation (Art. 12, CRC) and best interests of the child' (Art. 3, CRC). For instance, the available evidence suggests that the "best interests assessments" (BIA) and "best interests determination" (BID) procedures are not being used by the relevant national authorities and frontline professionals, particularly during asylum and immigration procedures (AEDH, 2017). In most of the EU Member States, the "best interests of the child" principle was not taken into account by the relevant national authorities and service providers (AEDH, 2017, UNICEF, 2018, House of Lords, 2016). For instance, in the UK, the "best interests of the child" principle was enshrined into national law by means of the Immigration Act 2009. However, the principle is often not observed in practice. According to the investigation carried out by the Independent Chief Inspectorate for Borders and Immigration (2018), the Home Office failed to pursue the "best interests of the child" of UAM s effectively in practice. According to the Independent Chief Inspectorate's findings, there was a clear 'failure [of the Home Office] to demonstrate that the child's "best interests" were a primary concern ... and that Home Office staff were not giving full consideration to the child's "best interests" in refusal decision letters' (Independent Chief Inspectorate for Borders and Immigration, 2018: 6, 8).

4 The UK has only opted into the first phase of CEAS and chose to not adopt the Family Reunification Directive. The Dublin III Regulation applies to the UK.

5 The UK adopted a scheme to enable a number of unaccompanied children to come to live safely in the UK - even if they did not have family links here. This was called the Dubs Amendment. It was named after a man who led the scheme that was being introduced, called Lord Alf Dubs. See: http://www.bbc.co.uk/newsround/3893250o.

6 See 'Protected on Paper? An analysis of Nordic country responses to asylum seeing children' (UNICEF, 2018). Available from: https://www.unicef-irc.org/publications/pdf/NORDIC\%2O 28\%2OLOWRES.pdf. 
In the UK, immigration concerns were generally prioritised over children's rights, and subsequently no attention was paid to the best interests of such children during the asylum and immigration processes which they experienced (House of Lords, 2016: 32).

While it has been evidenced that the Nordic states have been better at protecting the rights of UAM s, the interpretation of the "best interests of the child" also varied significantly in these countries, due to lack of a common approach to BID in practice. The absence of operationalisation of the "best interests" principle in practice, along with the "culture of suspicion and disbelief' (House of Lords, 2016) describing how UAM s were treated after arriving in Europe, were conducive to the detention of UAM s ${ }^{7}$ in adult detention centres for a significant amount of time in countries like the UK, Greece or Italy. Above all, as the European Commission's own assessment of the situation of UAM s demonstrates, the legislation of most Member States does not include a process for identifying and implementing the assessment of a "child's best interests", which should constitute the primary consideration in all actions and decisions that concern him/her (European Commission, 2017: 14).

Furthermore, the child participation principle, which is particularly crucial for UAM s given that he/she is the main source of information about his/her situation, fails to be taken into account in a meaningful way or at all during asylum procedures (House of Lords, 2016; Stalford, 2018). On the contrary, as evidence regarding the UK case demonstrates, child participation in asylum procedures involving UAM $s$ is not only underdeveloped, perhaps deliberately so, but also 'participatory opportunities are distorted and exploited by adult decision-makers who are operating under a rather more hostile agenda of exclusion and expulsion' (Stalford, 2018: 258). In the same vein, the implementation of child participation in asylum proceedings across Europe has been sketchy (House of Lords 2016).

Another important violation of children's rights is the age assessment procedure. Given the absence of a European accepted and non-invasive procedure of assessing UAM s' age medically, there is substantial evidence showing the use of non-medical age assessments primarily in the UK. The tendency to deploy intrusive and non-child friendly procedures to assess UAM s' age is rooted in the 'culture of disbelief and suspicion' (House of Lords, 2016:3) that national authorities display with respect to UAM s. This attitude towards UAM $s$ is prevalent in some of the main EU states that received refugees, such

7 For instance, in March 2017, the Court of Appeal's ruling criticised Home Office policy and claimed that immigration officers could not simply disbelieve the age given by child refugees (The Guardian, 9 March 2017). 
as the UK, Greece, Spain or Italy (Bhabha, 2018). There is strong reluctance to treat UAM $\mathrm{s}$ as children by believing their stories and narratives: ${ }^{8}$ this practice opposes the CRC recommendation ${ }^{9}$ which requires that in cases of uncertainty regarding children's age, they should be treated first and foremost as children until the contrary is proven..$^{10}$ There is evidence showing that national authorities go to great lengths 'scientifically' to disprove the reported age of UAM s by often using arbitrary and abusive age assessment procedures ${ }^{11}$ (AEDH 2017). Often national authorities disregard that UAM s should be given the benefit of the doubt, and subsequently, they are treated like adults, and often held in detention (Hungary, Helsinki Committee, 2017). This practice can have serious consequences for the welfare and well-being of UAM s: if they are considered adults rather than children, then in practice this means that they are denied access to welfare services and support, being placed in detention centres with adults, not being provided with a legal guardian and not receiving public funding for legal representation during the asylum process.

\subsection{Explanatory Factors}

The EU faced the recent crisis neither having a common position, nor being united in its approach. This lack of a clear EU policy and solidarity (Llewelly, 2016) to assist the refugees had consequences for the treatment of all refugees, including UAM s. According to a Human Rights Watch report, the EU and the Member States:

struggled to develop an effective and principled response to the hundreds of thousands of asylum seekers and migrants who reached Europe. Narrow government interests too often displaced sound policy responses, delaying protection and shelter for vulnerable people and raising questions about the union's purpose and limits (Human Rights Watch 2016).

8 See also Rosen and Crafter (2018) for the tabloid media's contestation of UAM s' authenticity regarding their claims.

9 According to the CRC, General Comment No. 6: "The assessment must be conducted in a scientific, safe, child and gender-sensitive and fair manner; avoiding any risk of violation of the physical integrity of the child; giving due respect to human dignity; and in the event of remaining uncertainty, should accord the individual the benefit of the doubt such that if there is a possibility that the individual is a child, s/he should be treated as such' (UN Committee on the Rights of the Child, 2005:10).

10 UN Committee on the Rights of the Child, General Comment No. 6 (2005).

11 For instance, some methods can include hair and genital examinations, which fail to respect the dignity of children and can often cause further trauma to a group of children who have already experienced significant trauma. 
Another factor that allowed the overlooking of UAM s' child rights was linked to financial pressures and a culture of disbelief across Europe regarding the UAM s' status, which led to national authorities' decision to overestimate the age of UAM s who lacked documentation in order to avoid having to take responsibility for a minor at a greater financial expense for the public budget (House of Lords, 2016). Financial reasons dictated how some of the EU Member States decided to deal with UAM s by circumventing aspects linked to their child rights protection, such as child participation (Stalford, 2018), while budget saving factors shaped how the "best interests of the child" was being determined in the UK (Humphris and Sigona, 2019).

Another key factor vis-à-vis UAM s' plight across Europe was the absence of integrated child protection systems, which should be focused on the best interests of the child and hence, should treat UAM s as first and foremost as children, whatever their immigration status. This is also an upshot of the existing tension between systems of care and restrictive immigration regimes which, in practice, leads to the denial of UAM s' rights (Chase, 2013). For instance, in most EU Member States, UAM s can be detained for immigration purposes and consequently, they are not integrated within national child protection systems with systematic oversight through guardianship and social work systems (UNHCR, 2018: 27). The failure of national child protection systems to protect and support UAM $s$ in a targeted and effective manner led to these children's becoming victims of trafficking and smuggling, as Europol's report, Migrant Smuggling in Europe ${ }^{12}$ (2016) showed. Data illustrates that children do not only go missing in countries of first arrival - due to their wish to continue their journey to Northern Europe - but also in countries of destination, such as the UK, Germany and Sweden (Missing Children Europe, 2017).

The failure to advance the rights of UAM s was an upshot of the Member States' policies to prioritise migration control over the protection of human rights. For instance, as the cases of the UK, Greece or Italy demonstrate, the policy focus is on the UAM s' 'immigration' status rather than on their status as 'children' (Council of Europe, 2018) with the aim of avowing the "pull" factor that UAM s could be. Given the precedence that the immigration context takes over the rights provision one, UAM s' child rights principles, such as the child's best interests and child participation, play a minor role. As a stakeholder put it, the 'immigration decision-making is key, while best interests' determination is a very piecemeal process, very superficial. ${ }^{13}$ 
The legal provisions in the CEAS generated limited opportunities, both for the protection of UAM s' rights in line with the CRC principles and for their effective enforcement during the asylum procedures. No wonder, therefore, that the European 'refugee crisis' was more accurately described as a 'crisis of the CEAS' (Niemann and Zaun, 2018). Indeed, the legal loopholes of the CEAS vis-à-vis child refugees (Smyth, 2014), along with the deficient implementation of EU asylum law at the domestic level (Lavenex, 2018), further exacerbated the plight of the UAM s across Europe by denying them the enforcement of their child rights, as enshrined in the CRC.

The violation of UAM s' child rights during the refugee crisis and the factors that explain some of these breaches shed light on the plight and suffering experienced by UAM s in Europe. However, a key underlying factor that contributed to the situation of UAM s was the diffusion of responsibility between various systems at the national level - horizontal diffusion - and between the EU, national and local levels, i.e.vertical diffusion. It is argued that this diffusion and fragmentation of responsibility for the protection of UAM s' rights acted as a catalyst by facilitating the role played by the other factors in obstructing the protection of UAM s. By applying the psycho-social concept of "bystander effect" to the policy interventions vis-à-vis UAM s at European and national levels, it is argued that the multitude of systems responsible for the protection of UAM s' rights suffered from lack of coordination and clear mandate, or responsibility, regarding the enforcement of UAM s' rights, which in practice further diffused the responsibility for their protection across various policy systems.

\section{1 'Bystander's Effect' and Diffused Responsibility}

In social psychology the "bystander effect" refers to the phenomenon that an individual's likelihood of helping others decreases when passive bystanders are present in a critical situation (Darley and Latane, 1968; Latane and Darley, 1970). In essence, the bystander effect ${ }^{14}$ refers to a situation where individuals are less likely to offer assistance in an emergency when other witnesses

14 In 1964, the story surrounding Kitty Genovese's murder was shocking enough to receive national media coverage. As Genovese returned to her New York City apartment one evening, she was followed by a stranger. In a stairwell plainly visible from other apartments, this stranger proceeded to attack her. During the next half hour, 38 of her neighbours heard her screams and witnessed her murder from their windows, but none called the police, much less intervened (Rosenthal, 1964/1999). 
are around: in psycho-social terms it suggests that the presence of a group prevents an individual from intervening in a case of emergency (Latane and Darley, 1970).

The bystander apathy effect is a widely-applied psycho-social concept showing that a person facing a situation of another person in distress, but who does so by knowing that others are also available to respond, is slower and less likely to respond to the person in distress than is a person who knows that he or she is the only one who is aware of the distress. Generally, this phenomenon was explained by conceptualisations drawing on diffusion of responsibility accounts, which focused on explaining how other actors present in the immediate situation influence would-be helpers' responses. The "bystander effect" raises an important challenge: namely, whether in emergency situations, there are clear lines of responsibility and intervention to assist someone needing help. According to the theory, an individual facing an emergency or a situation requiring assistance is likely to help (Latane, 1970). When other people are present, however, any given individual is significantly less likely to help. The likelihood of the emergency victim receiving help at all decreases as the number of bystanders increases (Latane and Darley, 1970). It has been claimed that one of the key factors conducive to the occurrence of the "bystander effect" is the diffused responsibility: namely in a situation where many bystanders can take action, responsibility becomes diffused as each individual feels he/she has only limited responsibility for the negative consequences of inaction (Hudson and Bruckman, 2004: 170).

According to Darley and Latane (1968), noticing and defining an event as an "emergency" does not necessarily mean that an individual will assume responsibility for intervening. One of the factors that Darley and Latane (1968) have explored is the effect of the number of other bystanders on intervention: the number of bystanders has an effect on the likelihood of intervention. When several bystanders are present the pressure to intervene is shared by all bystanders, and this is consistent with the concept of diffusion of responsibility. Other scholars (Cacioppo et al., 1986) linked the bystander apathy to a confusion of responsibility. This account suggests that would-be helpers are reluctant to help a victim in the presence of others because they do not wish to be perceived as the perpetrator of the victim's pain and suffering, which is the outcome of their uncertainty regarding their responsibility for that victim. Furthermore, Latane and Nida (1981) concluded that helping is reduced when the number of bystanders increases or when the situation is ambiguous (e.g. Clark and Word, 1974).

The "bystander effect" theory has been used in other disciplines, apart from psychology, to explain various social and political phenomena which entail 
contexts where individuals or states fail to act in emergency situations. For instance, sociological applications of the theory examined the factors which affect how the victim will respond to the bystander(s) who either provide or deny him assistance (Walster and Piliavin, 1972) or how in medical emergency situations, bystanders' intervention is much slower and less frequent if the victim's plight is serious (Piliavin et al., 1972). The "bystander" theoretical framework was also employed to explain the responsibility diffusion for mass atrocities that took place in Rwanda and Bosnia (Anderson and Brakstad, 2016). By drawing on the international principle known as the "responsibility to protect", Anderson and Brakstad (2016) show that the media's narratives of the genocide in these countries shaped the public discourse on the responsibility to protect at the political level, which encouraged a passive response, hence a diffused responsibility, from the international community vis-à-vis these mass atrocities. The extrapolation of a psychological concept, employed to explain individual behaviour relative to a group, to other disciplines has to uncover those mechanisms that explain the diffusion of responsibility at policy, societal or nation state levels. The focus on the protection failures of UAM $s$ during the refugee crisis allows for the identification of non-psychological factors that can justify the dispersed responsibility at domestic and European levels in relation to this group of child refugees.

The empirical analysis of this paper provides a unique conceptual bridging for the application of the "bystander effect" from the individual-group behaviour level to the state and supra-state level policies and practices. Indeed, the treatment of UAM s during the refugee crisis provides an excellent analytical testing ground for the "bystander effect" by shedding light on those specific mechanisms that allow for the diffusion of responsibility on a larger scale than the individual one. More specifically, some of the mechanisms or circumstances that blurred the responsibility lines for the protection of UAM s included the availability of a multiplicity of policy systems involved in upholding UAM s' rights at the domestic level, the lack of clear roles and lines of responsibility regarding the enforcement of UAM s' rights at the national and European levels, along with those specific aspects that should be prioritised regarding their situation, as well as the ambiguity regarding the nature of the crisis and how to address it most effectively.

The "bystander effect", understood as diffusion and confusion of responsibility in relation to the UAM s' rights protection, involves responsibility diffusion mechanisms at both national and supranational levels. At the domestic - or horizontal - level this diffusion entails the failure of responsibility allocation due to lack of effective coordination between various policy systems and the absence of an integrated approach to UAM s' protection. The second level 
encompasses the vertical diffusion of responsibility between EU, national and local levels. It is argued that this diffused responsibility across these dimensions originates both in policy design shortcomings as well as policy implementation deficiencies, augmented in particular by the overwhelming influx of refugees faced by Europe.

\subsection{Horizontal Responsibility}

Evidence shows that in most of the EU Member States that experienced high numbers of UAM s there was a lack of an integrated and multi-sectoral approach embraced by all the relevant policy sectors in relation to this group of child refugees. In practice, the responsibility lines vis-à-vis these children between various policy systems were blurred. This diffused responsibility was particularly obvious in the determination of "durable solutions" for UAM s, which requires a holistic intervention underpinned by a child-rights based approach. In the context of UAM s, a "durable solution" entails a "long-term and sustainable solution which ensures that the separated child is able to develop into adulthood in an environment which will meet his/her needs as well as fulfil his/her rights, not putting the child at risk of persecution or harm whilst also taking into account their views in accordance with their capacity' (The Children's Society 2015: 5). A "durable solution" can be local integration, repatriation or resettlement in a third country (UNHCR, 2007). According to current guidelines, determining durable solutions for UAM s should involve the adoption of a holistic and multi-disciplinary approach, involving all relevant professionals, such as immigration officials, social workers, healthcare and mental health services, child protection agencies etc. and underpinned by the "best interests of the child" determination and the inclusion of the voice of the child in all decision-making procedures (Irish Refugee Council, 2015).

However, the evidence illustrates the lack of formal, holistic and multi-disciplinary engagement, i.e. involving all relevant services and frontline professionals, policies and procedures to determine 'durable solutions', protective of child rights, for UAM s (The Children's Society, 2015; UNICEF, 2015; Irish Refugee Council, 2015). Indeed, it is unclear to what extent processes conducive to the adoption of durable solutions for UAM $\mathrm{s}$ are underpinned by key principles of the CRC, such as the promotion of the best interests of the child (Art.3, CRC) and child participation (Art.12, CRC). This lack of a comprehensive policy at the national level aimed at protecting the rights of UAM $s$ in a multi-disciplinary and multi-sectoral manner allowed for protection failures and rights violations (UNHCR, 2018). The absence of concerted action between the asylum/migration system and child protection one led to the problem of UAM s going missing, or becoming victims of child exploitation and trafficking, 
as happened in Greece and Italy (Digidiki and Bhabha, 2018). In other countries, such as the UK, the local care authority system and the immigration system run in parallel, which in practice undermines UAM s' right to protection (UNICEF, 2015). The fragmented policy interventions and poor cross-sectoral coordination to uphold the rights of UAM s diffused the responsibility for rights' protection ownership vis-à-vis this category of child refugees. Indeed, due to the involvement of a wide range of actors, inter-agency work, including responsibility allocation, were challenging (O'Donnell, 2018).

The plight of UAM s was particularly serious given that various authorities had to coordinate their policy interventions effectively in order to provide the necessary protection to this vulnerable group. In the case of UAM s, the duty bearers are represented by state authorities such as immigration authorities, social services, child protection agencies, health services, reception centre staff, legal guardians and law enforcement officials. The lack of a holistic, multi-sectoral approach to the protection of UAM s' rights facilitated by an ambiguous division of responsibility for upholding the child rights of the UAM $\mathrm{s}$ exposed them, in practice, to risks of trafficking and exploitation. In essence, the refugee crisis exposed structural shortcomings at policy coordination level regarding the protection of UAM s in Europe.

The available evidence shows that the child protection and immigration systems of the Member States could not cope with the overwhelming situation generated by the refugee influx. The unprecedented strain and pressure placed by the refugee crisis on national systems unveiled the already existing gaps and failures of these systems in coping with a crisis-like situation, as well as indicating deficient policy implementation, as the enforcement of child rights principles demonstrates, which further compounded the vulnerabilities and trauma suffered by UAM s on the ground (UNHCR, 2018). One of the reasons why child protection systems and services across the Member States failed to respond effectively to the influx of child refugees originated in the cuts in public services relevant to children and young people (Aldridge and Macinnes, 2014). This was particularly the case in countries such as Greece, Spain, Ireland and Portugal, which had been hard hit by austerity measures (Action for Children, The Children's Society and NCB, 2017) as well as the UK, where a cost-benefit analysis shaped the resourcing of children's services (Stalford, 2019). The scaling down of key children's services, particularly those relevant to UAM s, meant that the influx of refugees put pressure on a system that was already at a breaking point. ${ }^{15}$ The retrenchment of child protections services and the failure of the policy interventions to assist UAM s effectively

15 Interview with a child rights stakeholder, Brussels, 2018. 
and consistently led to a more systematic failure to advance a coherent approach to the protection of vulnerable children more generally by further undermining their health, safety and well-being. In practice this was aided by a diffusion of responsibility between the relevant policy systems as it was easy for them to pass the buck. As the case of Greece shows, the situation faced by UAM s there was 'evidence not of migration crisis per se, but of a crisis of child protection' (Digidiki and Bhabha, 2018: 114) which failed to assume the responsibility for their protection.

The evidence above demonstrates that, due to lack of coordination between various policy systems, as well as the absence of an integrated approach to the protection of UAM s, fragmented interventions were generated, as well as a vacuum of clear line of responsibility and ownership for upholding the rights of UAM s across Europe. This diffused responsibility to uphold UAM s' child rights in practice, as the evidence in section two illustrates, translated into grave implementation gaps vis-à-vis UAM s rights of the child (Bhabha and Abel, 2019).

\subsection{Vertical Responsibility}

The diffused responsibility for the protection of UAM s was also facilitated by the blurred fault line between the roles of the EU and national authorities for upholding the rights of UAM s. The EU asylum legislation provides minimum standards aimed at harmonising the protection standards and safeguards enjoyed by the UAM $s$ at the national level, and subsequently these legal provisions fall under the remit of the EU. Key CEAS laws include provisions that refer to the protection of UAM s in particular. For instance, Dublin III Regulation (EU) No. 604/2013 refers to the UAM s' reunification with family members in the territory of the EU by stipulating that child participation (Art. 12, CRC) should be taken into account in assessing their best interests, in accordance with their age and maturity; the Reception Conditions Directive 2003/9/EC and Qualification Directive 2004/83/EU on minimum standards for the qualification and status of third-country nationals or stateless persons as refugees require Member States to take measures conducive to the representation of UAM s by legal guardianship or, where necessary, representation by an organisation which is responsible for the care and well-being of minors. The Procedures Directive 2005/85/EC on minimum standards on procedures in Member States for granting and withdrawing refugee status also includes articles intended to protect UAM s' rights, such as the provision of legal representation throughout the asylum application process. These provisions show that, indeed, UAM s should be protected as part of the asylum process, which falls under the jurisdiction of the EU. 
However, the needs and legal entitlements of UAM s cross-cut other policy areas, such as child protection and social services. Indeed, most of the needs of UAM s outside the asylum framework should be met by the national child protection systems. While the CEAS rules cover the asylum dimension of the UAM s, the child protection aspect, as well as the broader issue of children's rights, should be provided at the national and local levels. Most importantly, local authorities play a key role in providing childcare and social services, including accommodation, access to education, social care and healthcare services, to name just a few. Nevertheless, the main problem linked to the vertical diffusion of responsibility is the poor coordination and lack of clarity between the responsibilities of the EU, national and local interventions to uphold the rights of UAM s. For instance, within the EU, there is no common agreement on how to assess children's age, leading to disparities in how children are treated during the asylum procedures in the Member States (AIDA, 2015). Furthermore, these disparities occur not only at Member State level, but also at the regional level within Member States (see EASO, 2013). Local and regional authorities have a key role in ensuring access to rights and child-friendly procedures, as well as providing UAM s with effective protection. However, as recent evidence from the Council of Europe shows, local authorities in most of the Member States failed to provide social services and care to UAM s in line with a childrights based approach (Council of Europe, 2018). Moreover, EU policies should be governed by the "principle of solidarity" between the Member States, yet the sharing of responsibility for vulnerable groups remains under negotiation between the EU States (O'Donnell 2018).

Another issue diffusing the responsibility for the protection of UAM $s$ is the poor cross-border coordination between the national authorities in charge of this group of child refugees. For instance, there is a general lack of systemic and consistent procedures to prevent the disappearance ${ }^{16}$ of children at the local level (Missing Children Europe, 2017: 11) as well as procedures for reporting missing children between the EU Member States. As stakeholders put it, 'clear ownership of missing children cases and cross border procedures need to be defined to facilitate prevention and response: while some of children might ... have been found or have found protection in another country, no-one knows' (cited in Missing Children Europe, 2017: 12). There is almost no inter agency cooperation, such as law enforcement agencies, to safeguard UAM s from going missing (Missing Children Europe, 2016) between the EU Member States. In the same vein, there are no mechanisms and procedures to allow cooperation

16 For instance, 10,000 UAM s have gone missing since 2015 (Europol cited in The Guardian, 30 January 2016). 
between the legal guardians and the relevant authorities ${ }^{17}$ of the countries to and from where the UAM s move. Indeed, there is no common EU approach to guardianship rules and appointment, despite the Fundamental Rights Agency's recently published guardianship guidelines ${ }^{18}$ (O'Donnell, 2018).

The inefficient cross-border interagency cooperation is further compounded by the complex domestic bureaucratic procedures and processes which further slowdown the speediness and effectiveness of national authorities' actions to return UAM s or report cases of missing UAM s. This has negative repercussions on the well-being of UAM $\mathrm{s}$ as the EU provides no guidelines or policy framework to assist this cross-border cooperation. Indeed, most often the country of arrival is not the country of UAM s' desired destination, which means that these child refugees are often on the move to countries such as Germany or the Nordic states which, subsequently, entails the need to have in place efficient mechanisms and procedures for cross-border cooperation among various national agencies, including law enforcement ones, responsible for the well-being of UAM s. This demonstrates that there are no clear responsibility roles between the EU and its Member States to address this kind of problem faced by UAM $\mathrm{s}$.

The diffusion of responsibility and the "bystander effect" consequences emerge from the clash of two main approaches regarding the UAM $s$ both at the EU and national levels: UAM s are framed, in policy terms, both as "vulnerable" children in need of protection, but also as potential economic migrants who abuse the system (Holmes and Castañeda, 2016). By focusing on the latter, and hence prioritising UAM s' migration status, including their vulnerability and passiveness, European and national officials can avoid highlighting the UAM s' agency and entitlement to have their rights protected as this can have implications for public perceptions about their right to be assisted and protected (see Erdal and Oeppen, 2018). In other words, the projection of a migration control policy approach at EU and national level removes the responsibility for protecting the UAM s' rights, particularly in line with a child rights approach.

In essence, these protection gaps highlight deeper structural problems concerning the situation of UAM s in Europe, determined by lack of a clear and coherent integrated approach to the protection of their rights both at the

17 According to a Belgian guardian: 'we cannot work with the authorities of other countries, and this is Europe. We know that children are going to these countries but we never have proof that they arrived. As legal guardian, if we could just get a call to say the child has arrived, it would be ok' (cited in Missing Children Europe, 2017: 12).

18 See Guardianship systems for children deprived of parental care. Available from: https://fra.europa.eu/sites/default/files/fra_uploads/fra-2018-guardianship-systemsin-the-eu-summary_en.pdf. 
EU and national levels. The so-called 'cracks in the system' (Rosen et al., 2017) exposed by the refugee crisis illustrated both the loopholes in the policy content as well as its deficient implementation. These shortcomings further fragmented the responsibility and accountability for the rights violations suffered by UAM $s$ across Europe. For instance, there is limited knowledge within local authorities about the specific health and well-being needs of UAM s (House of Lords, 2016) and it is widely known that the assessment of emotional and mental health is a complex process (Chase et al., 2008). In essence, there is limited policy coordination and coherence - regarding key protection policies for UAM s - between EU and national levels, which further translates into deficient implementation of policy interventions at the local level. This demonstrates the fragmentation of responsibility and protection ownership for the plight of UAM s.

\section{5}

\section{Conclusion}

This paper aimed to explore some of the reasons for the failure to protect UAM s' child rights during the refugee crisis. While not disregarding key factors discussed in the literature, such as the lack of European solidarity to share the help provided to refugees, legal loopholes, deficient policy implementation, prioritisation of migration control, along with cuts to social services across Europe, this paper argues that an underlying factor which facilitated the violation of UAM s' child rights was the diffused responsibility at European and national levels regarding how and which policy system should uphold the rights of this specific category of child refugees. It was claimed that the fragmented policy interventions and responsibilities - in upholding the rights of UAM s - both vertically, i.e. between the EU, national and local levels, as well as horizontally across national policy sectors - led to the UAM s' rights protection failure across Europe. By drawing on the "bystander effect" analytical framework, it was shown that the diffused or confused responsibility vis-à-vis UAM s manifested itself as an underlying factor that facilitated the deficient policy implementation and the prioritisation of migration control. This diffused responsibility is also an upshot of how multi-layered policy systems - such as asylum, migration, child protection, social services etc. - within a multi-tiered system of governance fail to work in a coordinated, multi-disciplinary and integrated manner due to structural design and implementation deficiencies. In essence, this obscured which policy system and tier of government should have taken the responsibility for the protection of UAM s' rights and, subsequently, should have taken the blame for the failure to do so during the refugee crisis in Europe. 


\section{References}

AEDH (European Association for the Defence of Human Rights), 2017, Asylum and Migration Policies. InEurope, unaccompanied minors are not protected.Available from: http://www.aedh.eu/en/in-europe-unaccompanied-minors-are-not-protected/.

AIDA (Asylum Information Database) 2015, Detriment of the Doubt: Age Assessment of Unaccompanied Asylum-Seeking Children, AIDA Legal Briefing No. 5, December 2015.

AIDA, 2017, The Concept of Vulnerability in European Asylum Procedures, available from: http://www.asylumineurope.org/sites/default/files/shadow-reports/aida_ vulnerability_in_asylum_procedures.pdf.

Aldridge, H. and Macinnes, T., "Multiple Cuts for the Poorest Families: 1.75 million of the poorest families have seen their benefits cut to date due to welfare reform" (2014) XXX.

Allsopp, J. and Chase, E., "Best interests, durable solutions and belonging: policy discourses shaping the futures of unaccompanied migrant and refugee minors coming of age in Europe", Journal of Ethnic and Migration Studies (2019) 45(2): 293-311.

Anderson, K. F. and Brakstad, I. V., "The Impossibility to Protect? Media Narratives and the Responsibility to Protect", Genocide Studies and Prevention: An International Journal, (2016) 9(3): 96-115.

Ayotte, W., Separated Children Coming to Western Europe: Why they travel and how they arrive (2000) (vol. 3), London: Save the Children.

Benhabib, S., The rights of others: Aliens, residents, and citizens (vol. 5) (Cambridge University Press: 2004).

Bhabha, J., "More than their share of sorrows: International migration law and the rights of children", Louis U. Pub. L. Rev. (2003) 22: 253-93.

Bhabha, J., "Arendt's Children: Do Today's Migrant Children have a right to have rights?", Human Rights Quarterly (2009) 31(2), 410-451.

Bhabha, J., Child migration and human rights in a global age (2014), Princeton University Press.

Bhabha, J., Can we solve the migration crisis?(2018), John Wiley \& Sons.

Bhabha, J., "Children on the move in twenty-first century: developing a rights-based plan of action", in Suárez-Orozco, M. M. (ed.)., Humanitarianism and Mass Migration: Confronting the World Crisis (California: University of California Press: 2019): 83-98.

Bhabha, J. and G. Abel, "Migration and Migrants: Regional Dimensions and Developments" (2019), 231-252.

Cacioppo, J. T., Petty, R. E., Kao, C. F. and Rodriguez, R., "Central and peripheral routes to persuasion: An individual difference perspective", Journal of personality and social psychology (1986) 51(5), 1032.

Chase, E., "Security and subjective wellbeing: the experiences of unaccompanied young people seeking asylum in the UK", Sociology of health \& illness (2013) 35(6): $858-872$. 
Chase, E., Knight, A. and Statham, J., Promoting the emotional wellbeing and mental health of unaccompanied young people seeking asylum in the UK (2008), London: Thomas Coram.

Clark, R. D. and Word, L. E., "Where is the apathetic bystander? Situational characteristics of the emergency" Journal of Personality and Social Psychology (1974) 29(3), 279.

Council of Europe, "Unaccompanied refugee children: the role and responsibilities of local and regional authorities" (2018) CG34(2018)13final, 28 March 2018.

Communication from the European Commission, "Commission to the European Parliament and the Council - Action Plan on Unaccompanied Minors 2010 - 2014", (6/5/2010 - COM (2010) 213 final.

Crawley, H., "No one gives you a chance to say what you are thinking': finding space for children's agency in the UK asylum system" (2010) Area, 42(2): 162-169.

Crock, M., Seeking asylum alone: A study of Australian law, policy and practice regarding unaccompanied and separated children (Federation Press: 2006).

Darley, J. M. and Latané, B., "Bystander intervention in emergencies: diffusion of responsibility", Journal of personality and social psychology, (1968) 8(4p1): 377 .

Digidiki, V. and Bhabha, J., "Sexual abuse and exploitation of unaccompanied migrant children in Greece: Identifying risk factors and gaps in services during the European migration crisis", Children and Youth Services Review, 92 (2018) 114-121.

EASO, Age Assessment Practice in Europe, December 2013. Available at: http://bit. ly/1NQGLTp.

Erdal, Marta Bivand and Ceri Oeppen, "Forced to Leave? The Discursive and Analytical Significance of Describing Migration as Forced and Voluntary", Journal of Ethnic and Migration Studies 44 (6) (2018): 981-998.

EU Observer (2017), "UN could step in where EU fails in child migrant protection". Available from: https://euobserver.com/stakeholders/137319.

European Commission, 2017, The Protection of Children in Migration, COM (2017)211 final, Brussels, 12 April 2017.

European Migration Network (2015), Policies, practices and data on unaccompanied minors in the EU Member States and Norway. Available from: http://ec.europa.eu/ anti-trafficking/sites/antitrafficking/files/emn_study_2014_uams.pdf.

Farmer, A., "Finding a new balance: bringing together children's rights law and migration policy for effective advocacy for migrant children" in Bhabha, J., Kanics, J. and Hernández, D. S. (eds.), Research Handbook on Child Migration (Edward Elgar Publishing: 2018): 173-186.

Guild, E., 'The Europeanisation of Europe's asylum policy', International Journal of Refugee Law (2006) 18(3-4): 630-651.

Hanson, K., “Killed by charity'-Towards interdisciplinary children's rights studies" (2014) 21(4): 441-46. 
Holmes, Seth M. and Heide Castañeda, “'Representing the 'European Refugee Crisis' in Germany and Beyond: Deservingness and Difference, Life and Death", American Ethnologist (2016) 43 (1): 12-24.

House of Lords, Children in crisis: unaccompanied migrant children in the EU, HL Paper (2016). Available from: https://publications.parliament.uk/pa/ld201617/ldselect/ ldeucom/34/34.pdf.

Hudson, J. M. and Bruckman, A. S., "The bystander effect: A lens for understanding patterns of participation", The Journal of the Learning Sciences (2004) 13(2): 165-195.

Human Rights Watch, 2016, Human Rights Watch World Report, 2016: European Union Events of 2015 Available from: https://www.hrw.org/world-report/2016/ country-chapters/european-union-o.

Humphris, R. and Sigona, N., "Outsourcing the 'best interests' of unaccompanied asylum-seeking children in the era of austerity", Journal of ethnic and migration studies (2019) 45(2): 312-330.

Hungary Helsinki Committee, 2017, Best Interest Out of Sight-The Treatment of Asylum Seeking Children in Hungary. Available from: https://www.helsinki.hu/wp-content/ uploads/Best-interest-out-of-sight.pdf.

Independent Chief Inspector of Borders and Immigration, 2018, An inspection of how the Home Office considers the 'best interests' of unaccompanied asylum seeking children, August-December 2017. Available from: https://assets.publishing.service. gov.uk/government/uploads/system/uploads/attachment_data/file/695310/An_ inspection_of_the_best_interests_of_unaccompanied_asylum_seeking_children_ March_2018.pdf.

Irish Refugee Council, 2015, "Durable Solutions for Separated Children in Europe". Available from: https:/www.irishrefugeecouncil.ie/wp-content/uploads/2015/11/ international_reportammended.pdf.

Latane, B., "Field studies of altruistic compliance", Representative Research in Social Psychology (1970).

Latané, B. and Darley, J. M., The unresponsive bystander: Why doesn't he help? (AppletonCentury-Crofts: 1970).

Latané, B. and Nida, S., "Ten years of research on group size and helping", Psychological bulletin (1981) 89(2), 308.

Llewellyn, S., 2016. 'Testing the solid in solidarity: An examination of why the on-going refugee crisis is the most important challenge facing the EU' Australian Institute of International Affairs, available from http://www.internationalaffairs.org.au/newsitem/testing-the-solid-in-solidarity-an-examination-of-why-the-on-going-refugeecrisis-is-the-most-important-challenge-facing-the-eu/.

Lavenex, S. "Failing Forward'towards which Europe? Organized hypocrisy in the common European asylum system", JCMS: Journal of Common Market Studies (2018) 56(5), pp.1195-1212. 
Missing Children Europe, 2016, Best practices and key challenges on interagency cooperation to safeguard unaccompanied children from going missing. Available from: http://missingchildreneurope.eu/Portals/o/Docs/Best\%2opractices\%2oand\%2o key\%2ochallenges\%2ofor\%2ointeragency\%2ocooperation\%2oto\%2osafeguard\%2o unaccompanied\%2omigrant\%2ochildren\%2ofrom\%2ogoing\%2omissing.pdf.

Missing Children Europe, 2017, Lost in Migration. Working Together in Protecting Children from Disappearance. Available from: http://lostinmigration.eu/Lost $\% 20$ in\%2oMigration\%20-\%2oBackground\%2onote\%2owith\%2opics.pdf.

Nakata, S., Childhood Citizenship, Governance and Policy: The Politics of Becoming Adult (Routledge: 2015).

Niemann, A. and Zaun, N., "EU refugee policies and politics in times of crisis: theoretical and empirical perspectives", Journal of Common Market Studies (2018) 56(1), 3-22.

O'Donnell, R., "Reflections on the European union's role in strengthening the protection of children in migration' in Bhabha, J., Kanics, J., \& Hernández, D. S. (Eds.) Research Handbook on Child Migration. Cheltenham: Edward Elgar Cheltenham: Edward Elgar, (2018) pp.131-139.

Piliavin, J. A. and Piliavin, I. M., "Effect of blood on reactions to a victim", Journal of Personality and Social Psychology (1972) 23(3): 353-361.

Pobjoy, J. M., The child in international refugee law (Cambridge University Press: 2017). Rosen, R. and Crafter, S., "Media representations of separated child migrants: From Dubs to doubt", Migration and Society (2018) 1(1): 66-81.

Rosen, R., Crafter, S. and Meetoo, V., A Warm Welcome? Unaccompanied Migrant Children in Networks of Care and Asylum, UCL: Social Science Research Unit (2017). Save the Children, 2017, European Refugee Crisis: Programme and Advocacy Report. Available from: https://reliefweb.int/report/world/european-refugee-crisisprogramme-and-advocacy-report-february-2017.

Smyth, C., European asylum law and the rights of the child (Routledge: 2014).

Stalford,H., "David and Goliath:Due Weight, the State and Determining Unaccompanied Children's Fate", Journal of Immigration, Asylum and Nationality Law (2018) 32(3): $25^{8-283}$.

Stalford, H., "The price is rights!: Cost benefit analysis and the resourcing of children's services", Children and Youth Services Review 99 (2019): 395-407.

The Children's Society, 2015, "Not just a temporary fix. The search for durable solutions for separated migrant children". Available from: https://www.childrenssociety. org.uk/sites/default/files/Durable\%2osolutions\%2odraft_FINAL\%2oDRAFT_ o.pdf.

UNHCR, 2007, "Refugee Protection and mixed Migration: A-10 Point Plan of Action". Available from: http://www.unhcr.org/4742a3ob4.pdf. 
UNHCR, 2018, Desperate Journeys. Refugees and migrants arriving in Europe and at Europe's borders. January-December 2018. Available from: https://data2.unhcr.org/ en/documents/download/67712.

UNHCR, 2018, "Desperate Journeys. Refugees and migrants arriving in Europe and at Europe's borders", December. Available from: https://www.unhcr.org/ desperatejourneys/.

UNICEF,2015, “Achievingadurablesolutionfortraffickedchildren”.Availablefrom:https:// www.unicef.org.uk/wp-content/uploads/2016/o1/Unicef_DurableSolutions_ Report2015.pdf.

UNICEF, 2018, "Refugee and Migrant Crisis in Europe. Humanitarian Situation Report \#26", 15 January. Available from: https://reliefweb.int/sites/reliefweb.int/ files/resources/UNICEF\%2oRefugee $\% 2$ oand\%2oMigrant $\% 20$ Crisis\%2oin $\% 20$ Europe\%2oSituation\%2oReport\%2oNo.\%2O26\%2O-\%2oDe....pdf.

UNICEF, 2018, "Latest statistics and graphics on refugee and migrant children". Available from: https://www.unicef.org/eca/emergencies/latest-statistics-andgraphics-refugee-and-migrant-children.

Vitus, K. and Lidén, H., "The status of the asylum-seeking child in Norway and Denmark: Comparing discourses, politics and practices", Journal of Refugee Studies (2010) 23(1), 62-81.

Walster, E. and Piliavin, J. A., "Equity and the Innocent Bystander", Journal of Social Issues (1972) 28(3), 165-189.

Watters, C., Refugee Children: Towards the Next Horizon (Routledge: 2007). 